\title{
Biomechanical Criteria for Estimating the Risk of Primary Open-Angle Glaucoma Progression
}

DOI: $10.17691 / \mathrm{stm} 2016.8 .4 .08$

Received May 4, 2016

E.N. Iomdina, DSc, Professor, Chief Researcher, Department of Refraction Pathology,

Binocular Vision Anomalies and Ophthalmoergonomics';

O.A. Kiseleva, MD, DSc, Head of the Department of Glaucoma';

I.N. Moiseeva, PhD, Senior Researcher, Laboratory of General Hydromechanics;

A.A. Stein, PhD, Leading Researcher, Laboratory of General Hydromechanics;

A.M. Bessmertny, MD, DSc, Senior Researcher, Department of Glaucoma';

A.Ju. Archakov, PhD Student, Department of Glaucoma';

O.M. Kalinina, MD, PhD, Researcher, Department of Glaucoma';

L.V. Vasilenkova, MD, PhD, Researcher, Department of Glaucoma';

G.A. Lyubimov, DSc, Professor, Chief Researcher, Laboratory of General Hydromechanics ${ }^{2}$

${ }^{1}$ Moscow Helmholtz Research Institute of Eye Diseases, 14/19 Sadovaya-Chernogryazskaya St., Moscow, 105062, Russian Federation;

${ }^{2}$ Research Institute of Mechanics, Lomonosov Moscow State University, 1 Michurinsky prospect, Moscow, 119192, Russian Federation

The aim of the investigation was to identify new biomechanical parameters characterizing elastic properties of the ocular corneoscleral shell and to determine their significance for estimating the risk of primary open-angle glaucoma (POAG) progression.

Materials and Methods. The study involved 41 patients (43 eyes) aged 55 to 72 (mean age $64.0 \pm 4.0$ years) with non-operated POAG, including 20 eyes with stage I POAG and 23 eyes with stage II, as well as 15 patients of the same age group with no eye pathology (except for age-related cataract) who served as control. The examination included Maklakov elastic tonometry with three different weights, differential Schiötz tonometry using a GlauTest 60 tomograph (Russia), optic nerve imaging using HRT3 (Germany), and static Humphrey (Germany) perimetry. All patients were re-examined 18 months after the initial examination.

Results. The biomechanical parameters were calculated based on mathematical modeling using elastic tonometry and differential tonometry data according to the method proposed by the authors. The value of a new parameter, elastic rise coefficient $\gamma_{M}$, characterizing mainly the rigidity of the cornea and determined using Maklakov elastic tonometry data averaged $0.88 \pm 0.20 \mathrm{~mm} \mathrm{Hg} / \mathrm{g}$ in stage I POAG and $0.80 \pm 0.04 \mathrm{~mm} \mathrm{Hg} / \mathrm{g}$ in stage II, whereas the control group showed an average of $0.86 \pm 0.07 \mathrm{~mm} \mathrm{Hg} / \mathrm{g}$. At the same time, we revealed increase in the other biomechanical parameter, elastic rise coefficient $\gamma_{S}$, characterizing mainly the rigidity of the sclera and determined according to Schiötz elastic tonometry data. Its value amounted to $1.65 \pm 0.25 \mathrm{~mm} \mathrm{Hg} / \mathrm{g}$ for stage I POAG and $1.88 \pm 0.13 \mathrm{~mm} \mathrm{Hg} / \mathrm{g}$ for stage II, with the mean of $1.47 \pm 0.10 \mathrm{~mm} \mathrm{Hg} / \mathrm{g}$ in the control group. It was found that with the value $K=\gamma_{S} / \gamma_{M}$ (an index showing the individual ratio of scleral and corneal rigidity) increasing above the threshold level clinical signs of glaucomatous process progression were observed.

Conclusion. The results indicate growing imbalance between biomechanical parameters of the sclera $\left(\gamma_{S}\right)$ and the cornea $\left(\gamma_{M}\right)$ during POAG development. The ratio of these parameters $\left(K=\gamma_{S} / \gamma_{M}\right)$ can serve as a measure of risk in progression of glaucomatous process related to the change in the state of the ocular corneoscleral shell.

Key words: glaucoma; corneal rigidity coefficient; scleral rigidity coefficient; elastic tonometry; cornea; sclera.

At present glaucomatous optic neuropathy is considered a multi-factor disease and impairment of biomechanical properties of the ocular corneoscleral shell is regarded to be one of the pathogenetic mechanisms [1, 2]. It has been established that biomechanical properties of the sclera and the cornea differ from each other and their change, on the one hand, influences the accuracy of intraocular pressure (IOP) measuring, on the other hand, impairs intraocular liquid hydrodynamics and predisposes to progression of glaucomatous process [1-7]. In this regard, clinical assessment of mechanical properties of the corneoscleral capsule has the undoubted diagnostic significance.

To assess the rigidity of the ocular corneoscleral shell clinically Maklakov tonometry and Schiötz tonometry are used. In case of elastic tonometry based on Maklakov tonometry elastic properties of the eyeball are usually characterized by elastic rise, i.e. the difference between two IOP measurements $\left(p_{2}-p_{1}\right)$ with different weights, these weights $\left(G_{2}\right.$ and $\left.G_{1}\right)$ being fixed (for example, 15 and $5 \mathrm{~g}$ ) [8].

In the calculations [9-11] published by us earlier

For contacts: Akhmed Y. Archakov, e-mail: archakov86@mail.ru 
function $p(G)$ showing dependence of tonometric pressure $p$ on weight $G$ was determined for each tonometer type. In a wide range of physiological parameter values these functions are close to linear ones, therefore it is possible to introduce some coefficient $y$ which we named elastic rise coefficient and determined using two measurements of tonometric pressure $p_{1}$ and $p_{2}$ with two different weights $G_{1}$ and $G_{2}$ from the formula $\gamma=\left(p_{2}-p_{1}\right) /\left(G_{2}-G_{1}\right)$. Elastic rise coefficients calculated according to different tonometer types for the same eye turn out to be different and are not expressed one through another, which is due to their different dependence on the two structural elastic parameters: rigidity of the cornea $\left(E_{c}\right)$ and rigidity of the sclera $\left(E_{s}\right)[10,11]$. In particular, as our previous calculations show, elastic rise coefficient $\gamma_{s}$ determined using Schiötz tonometry data turned to depend little on corneal rigidity and, thus, can serve as a characteristic of scleral rigidity $E_{s}$. At the same time, it does not coincide with Friedenwald rigidity also determined by Schiötz tonometry and differs from it in calculation method, dimension and distinct physical sense. On the other hand, coefficient $\gamma_{M}$, determined using Maklakov tonometry with different weights appears to be significantly dependent on both structural rigidities $E_{c}$ and $E_{s}$, but dependence on corneal rigidity is stronger $[10,11]$.

These model calculations have formed a basis for the development of a method to determine relative contribution of changes in elastic properties of the cornea and the sclera to the biomechanical component of glaucomatous damage related to the state of the ocular corneoscleral shell. They allow us to assess possible correlation of the imbalance between biomechanical parameters of the cornea and the sclera and primary open-angle glaucoma (POAG) progression.

The aim of the investigation was to identify new biomechanical parameters characterizing elastic properties of the ocular corneoscleral shell and to determine their significance for estimating the risk of primary open-angle glaucoma progression.

Materials and Methods. The study involved 41 patients (43 eyes) aged 55 to 72 (mean age 64.0 44.0 years) with non-operated POAG, including 20 eyes with stage I POAG and 23 eyes with stage II POAG. The control group included 15 somatically healthy patients (15 eyes) of the same age group with no eye pathology (except for age-related cataract). In patients with glaucoma IOP was compensated by hypotensive instillations throughout the examination.

The study complies with the Declaration of Helsinki (adopted in June 1964 (Helsinki, Finland) and revised in October 2000 (Edinburgh, Scotland)) and was performed following approval by the Ethics Committee of the Moscow Helmholtz Research Institute of Eye Diseases. Written informed consent was obtained from every patient.

All patients underwent Maklakov elastotonometry with weights of $7.5 \mathrm{~g}\left(G_{1}\right), 10 \mathrm{~g}\left(G_{2}\right)$ and $15 \mathrm{~g}\left(G_{3}\right)$. The corresponding tonometric measurements $p_{1}, p_{2}$ and $p_{3}$ were determined using Poliak's ruler. Then elastic rise coefficient $\gamma_{M}$ was calculated as the mean of two values $\gamma_{M 1}$ and $\gamma_{M 2}$ determined using the formulas: $\gamma_{M 1}=\left(p_{2}-p_{1}\right) /$ $\left(G_{2}-G_{1}\right)$ and $\gamma_{M 2}=\left(p_{3}-p_{2}\right) /\left(G_{3}-G_{2}\right)$. As mentioned above, $\gamma_{M}$ characterizes mainly the biomechanical status (rigidity) of the cornea $[10,11]$.

Differential Schiötz tonometry was performed on the same eye right after Maklakov elastotonometry using GlauTest 60 (Russia) with weights of 5.5 and $7.5 \mathrm{~g}$. The values of tonometric pressure were determined using characteristic curves obtained in GlauTest 60 mode, "Differential tonometry", and designed to determine rigidity coefficient $\mathrm{E}$. They were used to identify "penetration depths" of tonograph probe which were converted into tonometric pressure values $p_{1}$ and $p_{2}$, then elastic rise coefficient was calculated according to the formula $\gamma_{s}=\left(p_{2}-p_{1}\right) /\left(G_{2}-G_{1}\right)$. As stated above, $\gamma_{s}$ characterizes mainly the biomechanical status (rigidity) of the sclera $[10,11]$.

To evaluate the relative contribution of the cornea and the sclera to the formation of integral biomechanical status of the corneoscleral shell we considered it possible to introduce index $K=\gamma_{S} / \gamma_{M}$.

Clinical examination also involved assessment of optic disc structures by means of laser scanning tomograph HRT3 (Heidelberg Engineering $\mathrm{GmbH}$, Germany); evaluation of mean retinal nerve fiber layer thickness, rim volume, cup volume.

To evaluate the functional state of the vision system static perimetry was performed using Humphrey device (Carl Zeiss, Germany) with 30-2 Threshold test and SITA-Standard algorithm for determination of perimetric indexes MD (mean deviation) and PSD (Pattern standard deviation). This complex examination was carried out repeatedly 18 months later.

The obtained data were statistically processed using parametric criteria $\mathrm{M} \pm \sigma$ (mean value \pm mean deviation) and Student's t-test to compare the groups. Differences at $p<0.05$ were considered to be statistically significant.

Results. The values of elastic rise coefficient $V_{M}$ determined using Maklakov elastotonometry data varied from 0.7 to $1.1 \mathrm{~mm} \mathrm{Hg} / \mathrm{g}$ of weight in the control group and amounted to the average of $0.86 \pm 0.07 \mathrm{~mm} \mathrm{Hg} / \mathrm{g}$.

In patients with stage I POAG the values of this coefficient averaged $0.88 \pm 0.20 \mathrm{~mm} \mathrm{Hg} / \mathrm{g}$ and it was $0.80 \pm 0.04 \mathrm{~mm} \mathrm{Hg} / \mathrm{g}$ in stage II. Statistically significant differences of this coefficient from the norm were identified only in stage II POAG ( $p<0.05)$. Index $\gamma_{M}$ decreasing with development of glaucomatous damage can be estimated as the evidence of gradual change in biomechanical properties of the cornea, which may affect the accuracy of IOP measurement.

The values of elastic rise coefficient $\gamma_{s}$ determined using Schiötz differential tonometry data varied from 0.8 to $1.7 \mathrm{~mm} \mathrm{Hg} / \mathrm{g}$ in the control group and amounted to the average of $1.47 \pm 0.10 \mathrm{~mm} \mathrm{Hg} / \mathrm{g}$. In POAG the values of this coefficient were higher: in stage I they equaled $1.65 \pm 0.25 \mathrm{~mm} \mathrm{Hg} / \mathrm{g}$, and $1.88 \pm 0.13 \mathrm{~mm} \mathrm{Hg} / \mathrm{g}$ in stage II. 
It was found that with the value of $K=\gamma_{S} / \gamma_{M}$ (an index showing the individual ratio of the sclera and cornea rigidity) increasing above the threshold level clinical signs of glaucomatous process progression were observed. Here the differences of this index from the norm appeared statistically significant $(p<0.05)$ in stage II POAG. Since $\gamma_{s}$ reflects biomechanical properties of the sclera to a greater extent, the increase in this parameter in the process of POAG development is likely to indicate the change in scleral shell properties presenting as increase in its rigidity, which is consistent with conclusions made in other research papers [2, 6] and can be the cause of optic disc cupping.

The change in index $K=\gamma_{S} / \gamma_{M}$ suggested by us can serve as the evidence of imbalance between biomechanical parameters of the glaucomatous sclera $\left(\gamma_{s}\right)$ and cornea $\left(\gamma_{M}\right)$. The calculation of this coefficient (in the control group) showed that it varied from 1.4 to 2.4 amounting to the average of $1.90 \pm 0.22$.

At the same time increase in index $K$ averaging $2.15 \pm 0.75$ was noted in stage I POAG, while in stage II it amounted to $2.53 \pm 0.17$. The differences of this parameter from the norm become statistically significant $(p<0.05)$ in stage II POAG. These data speak of growing imbalance between corneal and scleral biomechanical properties during the disease progression.

To assess the possible role of the revealed imbalance as a risk factor for glaucomatous process progression the patients with coefficient $K=\gamma_{S} / \gamma_{M}$ deviating from the norm towards higher values were divided into three groups.

In group 1 (7 eyes with stage I POAG and 5 eyes with stage II) the deviation was insignificant and amounted to 0.1-0.3. In group 2 (8 eyes with stage I POAG and 10 eyes with stage II) it was $0.3-0.9$. In group 3 (5 eyes with stage I POAG and 8 eyes with stage II) it was 1.0 and more.

Eighteen months later changes in the studied structural-functional parameters were found only in $25 \%$ of cases ( 1 eye with stage I POAG and 2 eyes with stage II) in group 1 (with the minimal shift in coefficient $K$ in relation to the norm). Though, on average, these changes were statistically insignificant within the group (See the Table).

Simultaneously, in groups 2 and 3 in $67.7 \%$ of cases (8 eyes with stage I POAG and 13 eyes with stage II) certain changes in the studied structural-functional parameters were revealed at the end of follow-up period.

In group 2 where impairment of corneal and scleral biomechanical properties as well as imbalance between the studied biomechanical parameters were more pronounced than in group 1 statistically significant clinical and structural changes were observed: decrease in rim volume and increase in cup volume. Perimetric index PSD became statistically significantly higher in this group 18 months later.

In group 3 (with significant shift in coefficient $K$ values in relation to the norm) there were found significant changes in all studied structural-functional parameters (See the Table), which is consistent with glaucomatous progression.

Thus, impairment of biomechanical properties of the cornea and the sclera as well as imbalance between these parameters can be estimated as a risk factor for glaucomatous damage progression.

Conclusion. Assessment of elastic properties of the ocular corneoscleral shell using the method suggested by us showed their significant impairment in the course of primary open-angle glaucoma development. The presence of imbalance between biomechanical parameters of the sclera and the cornea (increases in the ratio $K=\gamma_{S} / \gamma_{M}$ ) can be considered a risk factor for primary open-angle glaucoma progression in patients with compensated intraocular pressure, which requires enhanced hypotensive measures or hypotensive operation to retard glaucoma progression. The obtained findings allow us to state that index $K=\gamma_{S} / \gamma_{M}$ is of diagnostic and prognostic importance for estimating the risk of glaucomatous progression.

Study Funding. This work was supported in part by the Russian Foundation for Basic Research (grant No.1401-00475).

Conflicts of Interest. There is no conflicts of interest related to the present study. 


\section{References}

1. Arutunyan L.L. Ocular biomechanical properties to set appropriate intraocular pressure target. Glaucoma 2007; 3: 60-67.

2. Iomdina E.N., Bauer S.M., Kotliar K.E. Biomekhanika glaza: teoreticheskie aspekty i klinicheskie prilozheniya [Eye biomechanics: theoretical aspects and clinical applications]. Moscow: Real'noe vremya, 2015; 208 p.

3. Iomdina E.N., Kiseleva O.A., Bessmertny A.M., Archakov A.Yu. Biomechanical studies of the corneoscleral shell in primary glaucoma. Rossiyskiy oftal'mologicheskiy zhurnal 2015; 8(3): 84-92.

4. Iomdina E.N., Kiseleva O.A., Nazarenko L.A., Ignatieva N.Yu., Bagratashvili V.N. The impact of biomechanical properties of the corneoscleral shell on eye hydrodynamics (an experimental study). Biomedicine 2012; 3: 25-34.

5. Costin B.R., Fleming G.P., Weber P.A., Mahmoud A.M., Roberts C.J. Corneal biomechanical properties affect Goldmann applanation tonometry in primary open-angle glaucoma. J Glaucoma 2014; 23(2): 69-74, https://doi. org/10.1097/ijg.0b013e318269804b.

6. Crawford Downs J., Roberts M.D., Sigal I.A. Glaucomatous cupping of the lamina cribrosa: a review of the evidence for active progressive remodeling as a mechanism. Exp Eye Res 2011; 93(2): 133-140, https://doi.org/10.1016/j. exer.2010.08.004.
7. Svetikova L.A., lomdina E.N., Kiseleva O.A. Biomechanical and biochemical parameters of the corneoscleral capsule of patients with primary open-angle glaucoma. Rossiyskiy oftal'mologicheskiy zhurnal 2013; 6(2): 105-112.

8. Nesterov A.P. Glaukoma [Glaucoma]. Moscow: Meditsina; 1995; 256 p.

9. Iomdina E.N., Lyubimov G.A., Moiseeva I.N., Stein A.A., Kiseleva O.A., Archakov A.Yu. Vozmozhnosti klinicheskoy otsenki mekhanicheskikh svoystv korneoskleral'noy kapsuly pri glaukome s pomoshch'yu tonometricheskikh metodov. V kn.: Materialy VIII Rossiyskogo obshchenatsional'nogo oftal'mologicheskogo foruma. T. 2 [Features of clinical evaluation of the mechanical properties of the corneoscleral capsule in glaucoma using tonometric methods. In: Proceedings of the VIII Russian national ophthalmology forum. Vol. 2]. Moscow; 2015; p. 678-687.

10. Moiseeva I.N., Stein A.A. Analysis of the pressurevolume relationship for the eyeball loaded by a flat stamp on the basis of a two-segment elastic model. Fluid Dynamics 2011; 46(5): 673-683, https://doi.org/10.1134/ s0015462811050012.

11. Stein A.A. O ponyatii rigidnosti glaza. V kn.: Materialy IV Rossiyskogo obshchenatsional'nogo oftal'mologicheskogo foruma. T. 2 [On the concept of eye rigidity. In: Proceedings of the IV Russian national ophthalmology forum. Vol. 2]. Moscow; 2011; p. 257-261. 